\title{
Indigenous Knowledge of the Edible Weaver Ant Oecophylla sma- ragdina Fabricius Hymenoptera: Formicidae from the Vientiane Plain, Lao PDR
}

\author{
Joost Van Itterbeeck ${ }^{1 *}$, Niane Sivongxay ${ }^{2}$, Bounthob Praxaysombath ${ }^{2}$, and Arnold van Huis ${ }^{1}$ \\ Author address: ${ }^{1}$ Laboratory of Entomology, Department of Plant Sciences, Wageningen University, Droevendaalsesteeg 1, \\ 6708 PB Wageningen, the Netherlands, '2Department of Biology, Faculty of Science, National University of Laos, Ban \\ Dongdok, Vientiane, PO Box 7322. \\ "Corresponding Author: joostvanitterbeeck@hotmail.com
}

Received: September 25, 2013

Volume: 5:4-12

Published: January 13, 2014

(c) 2014 Society of Ethnobiology

\begin{abstract}
Of major importance in realizing the potential of edible insects as a core element in improving food security, sustainable food production, and biodiversity conservation, are developments in sustainable exploitation of wild edible insect populations and in (semi-)cultivating and farming edible insects. Such developments can draw on both western science and indigenous knowledge. Oecophylla smaragdina Fabricius Hymenoptera: Formicidae, of which particularly the queen brood is commonly consumed in Thailand and the Lao PDR, is believed to have the potential to act as flagship/umbrella species in forest conservation and management, to be incorporated simultaneously as biological control agent and direct source of human food in agroforestry practices, and to be (semi-)cultivated. We provide a detailed account of indigenous knowledge of $O$. smaragdina and ant brood collection practices from the Vientiane Plain, Lao PDR, through focus group discussions and participant observations, and then reflect on sustainability and conservation issues, and on semi-cultivating constraints and possibilities embedded in indigenous knowledge and ant brood collection practices.
\end{abstract}

Key Words: Oecophylla smaragdina, entomophagy, edible insects, indigenous knowledge, Lao PDR, semi-cultivation, agroforestry

Introduction

Edible insects are a possible core element in improving food security, sustainable food production, and biodiversity conservation, in particular in developing countries accustomed to entomophagy. Of major importance in realizing these potentials are developments in sustainable exploitation of wild edible insect populations and in (semi-)cultivating and farming edible insects (defined in van Huis et al. 2013), which can draw on both indigenous knowledge and western science (Durst and Shono 2010; van Huis et al. 2013). As such, Ramos-Elorduy (2006) points to nontraditional collection practices threatening 14 edible insect species in Hidalgo, Mexico, and the need for preservation measures; Ayieko et al. (2011) combine indigenous technological knowledge and modern technology in Kenya in developing a termite (Macrotermes subbylanus Isoptera: Macrotermitidae) mass collection device; and Choo et al. (2009) show how Amerindians use traditional ecological knowledge in the cultivation of palm weevils (Rhynchophorus palmarum Linnaeus Coleoptera: Curculionidae, Rhinostomus barbirostris Fabricius Coleoptera: Curculionidae).

The Asian weaver ant Oecophylla smaragdina Fabricius Hymenoptera: Formicidae (Figure 1) is one of the most favoured edible insects in the Lao PDR (H. Barennes 2010 personal communication) and Thailand (Sribandit et al. 2008). The O. smaragdina use as human food concerns predominantly the brood (i.e., eggs, larvae, pupae), particularly the seasonally available large larvae and pupae - the queen brood that develop into winged reproductive females known as virgin queens. Sribandit et al. (2008) showed the economic importance of $O$. smaragdina queen brood trade to rural livelihoods in Northeastern Thailand. There is every reason to assume a comparable economic importance in the neighbouring, and culturally similar, Vientiane Plain, Lao PDR, where rural people are highly dependent on non-agricultural 


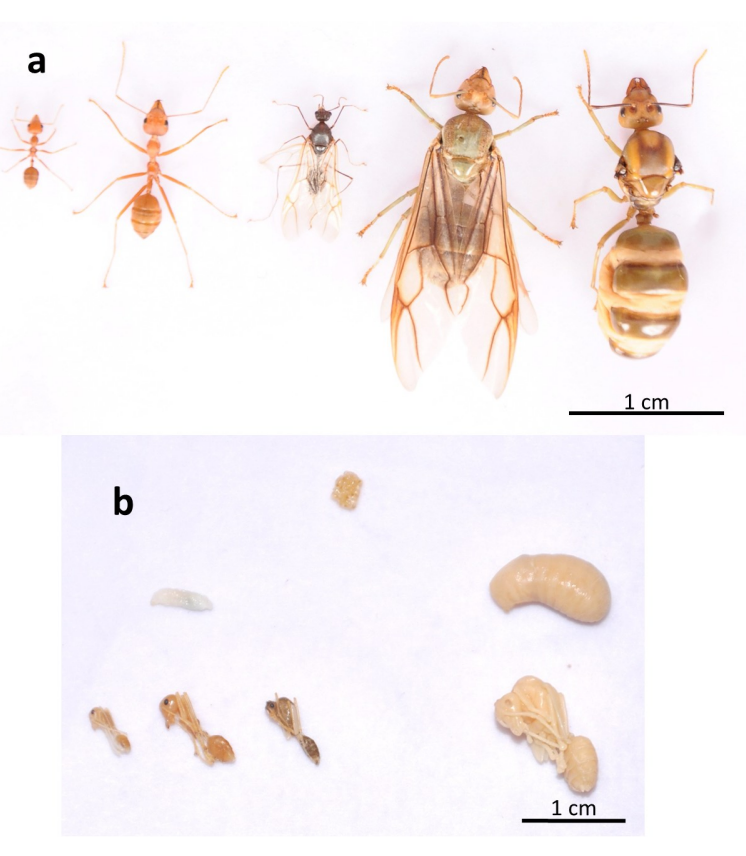

Figure 1. (a) O. smaragdina castes. From left to right: minor worker, major worker, male, virgin queen, egglaying queen. (b) O. smaragdina brood. Top: egg cluster. Middle row: small and large larva. Bottom row, from left to right: pupae of minor worker, major worker, male, and virgin queen. (Photos by Van Itterbeeck.)

resources, including edible insects (Meyer-Rochow et al. 2008).

O. smaragdina is an arboreal ant that builds nests by binding living leafs together. Its colonies are polydomous, consisting of multiple nests. As an aggressive and generalist predator it can control a number of pest insects of mango, cashew, citrus, and other crops (Crozier et al. 2009). Offenberg and Wiwatwitaya (2010) suggest that the traditional Thai collection practice of O. smaragdina does not conflict with the biological control capability of this ant species in orchards. Considering the large variety of commercially valuable $O$. smaragdina host plants, its potential in agroforestry practices is apparent (Lim 2007; Van Mele 2008). Currently though, O. smaragdina, of ecological importance as an abundant and territorially dominant ant species in Southeast Asia, northern Australia, and the Pacific (Crozier et al. 2009) is primarily collected in forests.

The abundance, biological control capability, and relative sessile character of $O$. smaragdina colonies (Rastogi 2007) may be particularly beneficial to further developments in the exploitation of $O$. smaragdina. This species may have the potential to act as a flagship and/or umbrella species in forest conservation and management, it may be used both as biological control agent and human food source in agroforestry practices, and it might be (semi-) cultivated to increase queen brood predictability and availability (van Huis et al. 2013; Offenberg and Wiwatwitaya 2010). Issues pertaining to sustainable use and biodiversity conservation, and biological mechanisms underlying the predictability and availability of the O. smaragdina queen brood resource are likely embedded in indigenous knowledge which can provide the basis for such further developments (Berkes 2008; Durst and Shono 2010; van Huis et al. 2013). The aim of this paper is therefore to provide a detailed account of indigenous knowledge of the weaver ant O. smaragdina from the Vientiane Plain, Lao PDR, and to reflect on sustainability and conservation issues, and on (semi-)cultivating constraints and possibilities from a biological and practical perspective.

\section{Methods}

The research was conducted in the southern half of Xaythani District, Vientiane Municipality, Lao PDR. Three rural villages, Ban Dongbang, Ban Dongmakkhai, and Ban Sanghouabor (Figure 2), were randomly sampled. Land use and demographic data are summarized in Table 1.

Our informants were expert ant brood collectors, who are well-known for their expertise in their village. Each head of village, with aid of his assistants, invited the experts in their villages to participate in the research, and most of the people who were invited responded positively. All the expert collectors stated they are farmers growing rice in the rainy season (May - October). Some farmers irrigate their fields in the dry season (November - April) allowing for a second, yet shorter, period of rice cultivation. All collect a large variety of Non-Wood Forest Products throughout the year, including fish, edible insects, mushrooms, bamboo shoots, and fruits. Most informants supplement this with keeping a vegetable garden. Informants' ages ranged between 25 and 70, most were female.

Information was compiled through focus group discussions and participant observation. Focus group discussions were held in December 2010 using a semistructured questionnaire. To cover all topics of the questionnaire sufficiently, two group discussions were 


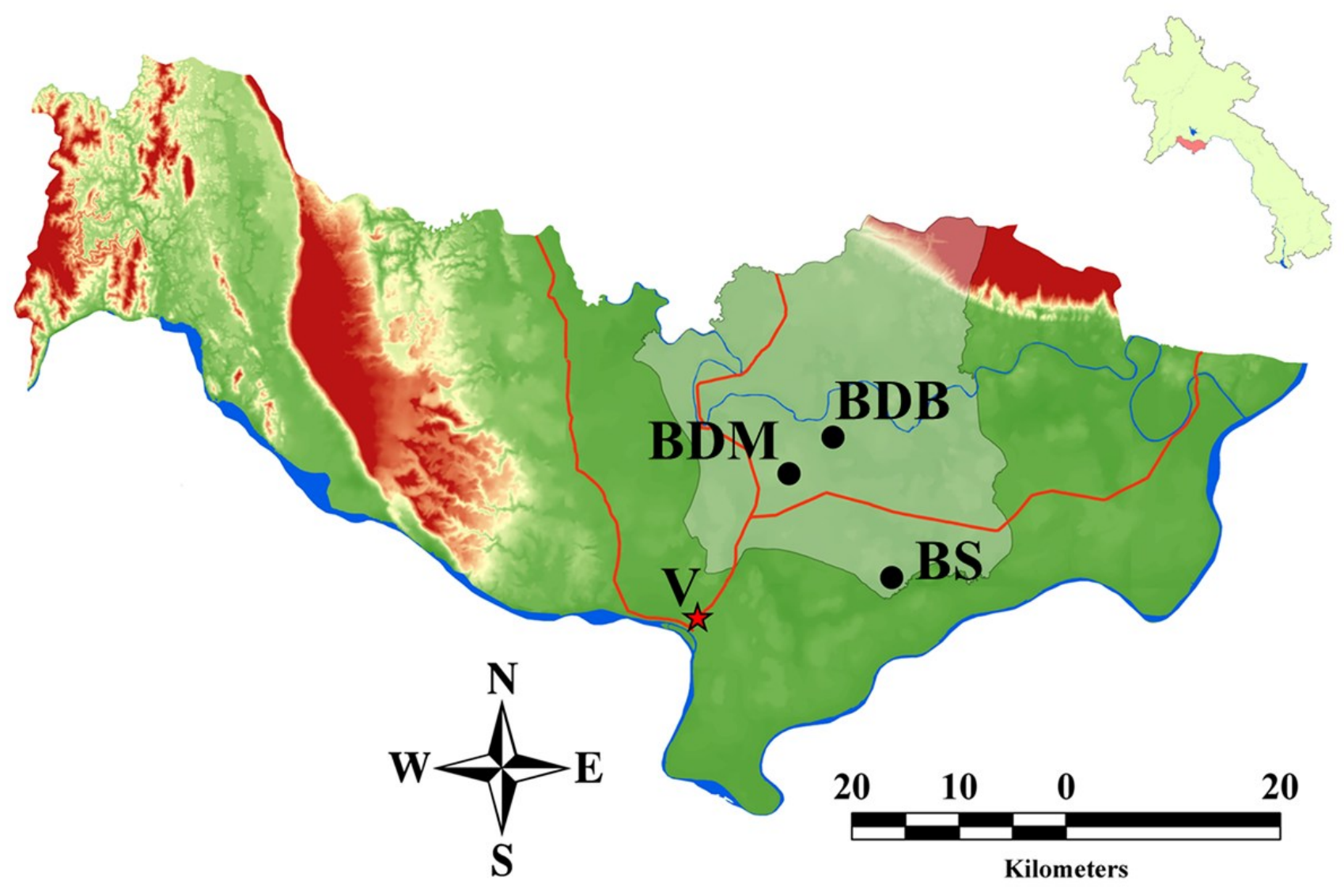

Figure 2. The location of the three research sites, Ban Dongbang (BDB), Ban Dongmakkhai (BDM), and Ban Sanghouabor (BS), in Xaythani District (shaded area), Vientiane Municipality, Lao PDR. V = Vientiane Capital. (Source: Soulixay Inthasone, Faculty of Environmental Sciences, National University of Laos).

conducted in each village. At the start of each session, informed consent was received collectively on recording the discussion (digital voice recorder). Attendance ranged between 7 and 21 people. The questionnaire focussed on biological and ecological aspects of $O$. smaragdina including reproduction, castes, developmental stages, behaviour, nest characteristics, and host tree characteristics, and on harvesting methodologies and their effect on the ants. Using an A1 size print of the village and its direct surroundings, different areas were discussed in terms of $O$. smaragdina abundance and yields.

Participant observations were conducted from January to April 2011. At least four expert collectors were followed in each of the three villages independently of each other and on at least two separate ant brood collecting trips. All but two expert collectors attended focus group discussions. Collecting trips typically lasted from morning (8 AM) until noon (12 $\mathrm{AM}$ ), but sometimes continued into the afternoon (between 2-4 PM). Observations were made on harvesting tools and techniques, localities, external characteristics of nests and their contents, and informal discussions were held during the trips using the aforementioned questionnaire. The focus group discussions were thus verified with individuals during these collecting trips, and additional and more detailed information could be acquired. When an opposing view was encountered, it was verified with other experts.

Lao words are written in standard international phonetic alphabet but excluding signs for intonation and taken from the Lao-English/English-Lao Dictionary (Mingbuapha and Poomsan Becker 2003). Spelling marked * is written by the first author. The most frequently used vernacular names are given. 
Table 1. Land use and demographic data of the three research sites.

Population*

\begin{tabular}{|c|c|c|c|c|c|c|c|c|c|c|}
\hline & $\begin{array}{c}\text { Number of } \\
\text { house- } \\
\text { holds* }\end{array}$ & Male & Female & $\begin{array}{l}\text { Forest^^} \\
\left(\mathrm{km}^{2}\right)\end{array}$ & $\begin{array}{l}\text { Paddy } \\
\text { field^ } \\
\left(\mathrm{km}^{2}\right)\end{array}$ & $\begin{array}{c}\text { Water } \\
\text { body^ } \\
\left(\mathrm{km}^{2}\right)\end{array}$ & $\begin{array}{c}\text { Residen- } \\
\text { tial area^ } \\
\left(\mathrm{km}^{2}\right)\end{array}$ & $\begin{array}{c}\text { Vacant / } \\
\text { arable } \\
\text { land^ } \\
\left(\mathrm{km}^{2}\right)\end{array}$ & $\begin{array}{c}\text { Rainy } \\
\text { season / } \\
\text { head }\end{array}$ & $\begin{array}{c}\text { Dry season } \\
\text { head }\end{array}$ \\
\hline Ban Dongbang & 163 & 560 & 433 & 1.38 & 3.13 & 0.05 & 0.37 & 0.00 & 0.47 & 0.05 \\
\hline $\begin{array}{l}\text { Ban } \\
\text { Dongmakkhai }\end{array}$ & 314 & 861 & 823 & 6.51 & 5.91 & 0.19 & 0.64 & 0.76 & 0.89 & 0.03 \\
\hline $\begin{array}{l}\text { Ban } \\
\text { Sanghouabor }\end{array}$ & 157 & 537 & 415 & 4.81 & 5.10 & 0.40 & 0.19 & 0.29 & 0.40 & 0.02 \\
\hline
\end{tabular}

* National Statistics Center (2009)

${ }^{\wedge}$ Calculated by Mr Soulixay Inthasone, Faculty of Environmental Sciences, National University of Laos, using ArcMap

Office of Agriculture of Xaythani District (2007-2008)

\section{Perception on Caste and Life Cycle}

The prime vernacular name of the Asian weaver ant, mot som (mot $=$ ant, som $=$ sour $)$, comes forth from its use as food (worker ants taste sour). The secondary name, mot dkeng (dkcng = red), is derived from appearance (worker ants are colored red).

The expert collectors indicate that major workers guard the nests to protect its contents because many run out of a nest when disturbed and bite fiercely while releasing a liquid, "pee" (this is formic acid). They construct nests by pulling leaves together, e.g., through forming a living chain, thereafter held in place by a white substance ("pee" as above but in this case larval silk). Major workers collect food as the collectors see them carry insects, and various insect remains are found among the collected brood.

Because of these behaviors, our respondents believe that major workers are mothers that lay eggs and care for their brood. They regard each ant an individual that cooperates with any other mot som "all are family" - and compare ants to higher organisms, e.g., humans and their protective behavior towards their young. Major workers are hence

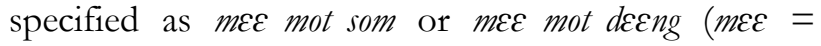
mother, and refers to 'female'). They may also be called mec phan* (phan* refers to sexual intercourse and fertilization) as several collectors indicate that only after an act of sexual intercourse ants can lay eggs. Sexual intercourse is assumed to occur inside a nest; undisturbed behavior inside the nests cannot be witnessed by the respondents and they acknowledge it remains open to speculation.

Consequently, identification of a father shows less consensus. Some respondents do not know of the existence of a father. Others claim that major workers with a larger gaster (the hind body part) are mothers, and those with smaller gaster are fathers. Minor workers (no specific vernacular name), which are rarely seen outside a nest, are believed to be young ants due to their smaller body size than major workers.

The informants refer to the brood as ant 'eggs', kai mot som $(k a i=\mathrm{egg})$. True eggs are specified as kai nכวi nวэi (nכวi nวכi $=$ very small). When collecting ant brood, these are seen sticking on the leaves in the nest interior and in chambers made from "pee" (larval silk). Eggs are indicated to become larvae, kai $f^{*}$ ( $f a^{*}$ refers to small size). Some of them become large larvae, kai khok* or kai teung* (khok* and teung* refer to large size) (Figure 1b, and see seasonality below). The informants explain the difference in size of the larvae by the amount of food and water received.

Larvae then develop into pupae, specified as naang, meaning young lady, one which is not married yet (as used for human girls). Small pupae are called kai naang or naang $f a^{*}$, large, queen destined pupae are called mec naang. Small pupae change their white color into either red or black. The former develop into

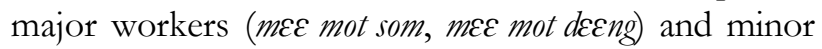
workers, the latter into winged black ants, mec dam (dam = black) (these are males). Male pupal wing formation is also recognized. Large larvae (kai khok*, 
kai teung*) and large pupae (mer naang)-become virgin

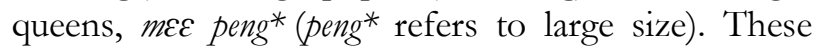
pupae change their white color first into yellow.

An explanation for the existence of either of the

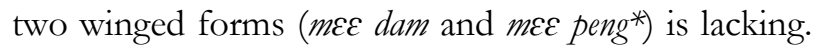
Our informants merely state that "it is nature" to produce them. Winged forms are known to leave their nest of origin by flight. Prior to their flight, the virgin queens are indicated to change their yellow color to green and strengthen their wings. No collector could provide neither a reason for them leaving their nest nor indicate where they fly to. They assume that these will become food for other animals and thus do not regard them to have long life.

Very few collectors know of a big-bottomed ant, lacking wings but able to crawl (this is the egg-laying queen). She was called bua-naa nyai (bua-naa $=$ boss, nyai $=$ big) by one respondent on our only occasion encountering her during participant observation. A similar description is given to a caterpillar (Liphyra brassolis brassolis Westwood Lepidoptera: Lycaenidae) occasionally found live in large nests though it is not recognized as such. They say it looks like a pillow and is hence called mכon mot decng ( $m$ כon = pillow). Pictures of both egg-laying queen and L. brassolis brassolis butterflies were shown to Ban Sanghouabor informants but none recognized one or the other. Since rarely encountered, major workers are believed to produce neither bua-naa nyai nor moวn mot decng often. Their existence and function remained unexplained, and they are, rather jokingly, referred to as "big boss", drawing comparison to human social organization. When found, they may be consumed.

Total development time of the castes could not be clearly indicated by our respondents.

\section{When and Where to Collect? \\ Seasonality and the role of water}

Queen brood availability determines the ant brood collecting period which peaks in March. Worker brood production is known to occur throughout the year. However, the collectors observe an increase in major worker numbers in January and February, prior to the production of virgin queens in February, March, and April, and males in May. Overlap occurs. They explain the increase in workers by the need of a lot of mothers to produce many large 'eggs' (queen brood).

Local differences in availability are indicated: in the vicinity of water (e.g., a pond) queen brood production is sooner than elsewhere as queen brood is believed to drink a lot of water to become large. These areas are frequented from February onwards. Further, in February/March periods of rain are expected which is said to accelerate larval growth.

\section{Forest and tree characteristics}

To collect ant brood, a bamboo stick $(4-6 \mathrm{~m})$, with sharpened tip and a strong bag or a bamboo basket attached behind this tip is used to pierce through a nest. By shaking the stick and/or hitting it with flat hand, the nest contents (all castes and developmental stages) falls into the bag/basket, hanging beneath the nest (Figure 3). The collection of queen brood thus implies the collection of worker ants and small-sized brood which develops into minor workers, major workers, and males; these are also consumed and marketed.

The majority of collection occurs along forest edges and paths mainly due to the ease of maneuvering with a long stick. Many nests can be found away from these zones but are generally only harvested from or sought for when (1) a large nest is seen from the edge/path, (2) promising trees are seen from the edge/path (e.g., the evergreen Syaygium cumini Skeels Myrtaceae, ton $\left.w a^{*}\right)$, (3) the collector is not satisfied

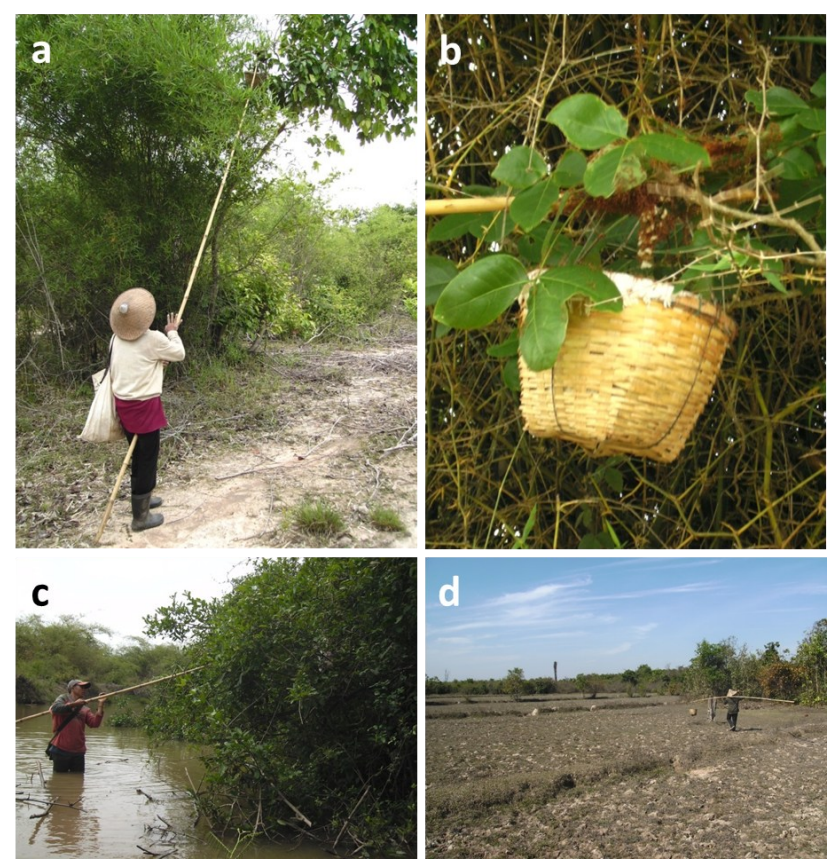

Figure 3. (a) Collecting ant brood along a forest path. (b) Nest contents falls into the basket. The large brood and worker ants are clearly visible. (c) Collecting ant brood along a stream. (d) Collecting ant brood along the forest edge. (Photos by Van Itterbeeck.) 
with the number of nests found along the edge/path, and (4) trees are scattered. Trees in dry dipterocarp forest $\left(k h^{*}\right)$ in the research sites are particularly scattered, edges and paths may be disregarded altogether. Dry evergreen forest (dong*) is said to be less suitable for nesting because it is too dense. Collectors do 'island hopping': nests are found in trees amid paddy fields, usually growing on termite hills.

\section{Which nests to collect from?}

Collectors use three primary criteria on the external appearance of nests to indicate relative high queen brood yield: (1) nest size, (2) leaf color, and (3) external visibility of larval silk. Relative refers to the ratio of large-sized brood (i.e., late queen larvae instars and queen pupae) to small-sized brood (i.e., worker and male brood, and early queen larvae instars), and the positive relation between nest size and nest contents.

Although all nests are said to contain queen brood, it is acknowledged some do not ("built only to live in"). Large nests (estimated $>30 \mathrm{~cm}$ diameter) are aimed for. However, it is known that medium- and small-sized nests are more abundant. While medium nests (estimated $10-20 \mathrm{~cm}$ diameter) are also targeted, small nests $(<10 \mathrm{~cm}$ diameter) are generally ignored due to a very small yield. Relative queen brood yield is expected to be high from any nest with partly green and partly dried leafs and plenty of larval silk visible on the nest exterior.

Collectors mention two additional criteria: (1) bending of the supporting branch indicates a heavy nest thus with high relative queen brood contents and (2) nests easily shaken by wind are light thus contain little small-sized brood only or no brood at all.

Apart from the small nests, few along the route taken may escape (severe) disturbance: (1) recently disturbed nests as they contain only small-sized brood (but only very recent disturbance is recognized easily), (2) nests that are too high up in the tree (but sometimes two bamboo poles are attached to each other to reach them), (3) unnoticed nests (e.g., 'hidden' behind branches and leafs), (4) nests that are not emptied when probing yields only small-sized brood (nests are then allowed to be repaired such that the remaining brood can develop further), (5) nests that are ignored when others in the same tree lack queen brood, and (6) nests close to a large nest containing queen brood (not expected to contain such brood). Correct predictions of nest contents are difficult to make, therefore the collectors usually refrain from doing so.

\section{Discussion \\ Ecological implications}

The collection practices applied by our informants seem to assure colony survival for two reasons. First, the queen, who is the principal egg-layer (Hölldobler and Wilson 1990), is very rarely, yet unintentionally, removed and she is unknown to most collectors (colonies that produce sexual forms have a single queen [Van Itterbeeck et al. in preparation]). This is because her nest is small and located near the top of a tree (Van Itterbeeck et al. in preparation). Small nests are generally ignored $-a$ positive relation exists between nest volume and contents (Gupta 1968) and may remain undetected when near the top of a tree. Removal of the queen would result in the death of the colony since Oecophylla spp. workers can only produce males (Hölldobler and Wilson 1983) and queen turnover - the acceptance of a new queen (Heinze and Keller 2000) - does not seem to occur in O. smaragdina (Van Itterbeeck et al. in preparation).

Second, the participant observations made on collection practices suggest that a large fraction of a colony remains undisturbed, although most nests are easily detected and the average tree height allows most nests to be reached. This is intentional as small nests yield small amounts of queen brood (or none at all) and collectors refrain from removing large amounts of 'mother' worker ants. Therefore, it is likely that the fraction of workers and new worker brood removed by collection does not impede foraging nor defense, and thus does not impede the maintenance of an individual colony and its role in forest ecology.

The maintenance and survival of a population of O. smaragdina colonies on the other hand greatly relies on the reproductive castes - not required for the survival of parent colonies - as an ant colony could be viewed as a single reproductive organism, a 'superorganism', which produces daughter colonies (Hölldobler and Wilson 2009). In ants, sexual intercourse occurs between males and virgin queens which conduct a mating flight (nuptial flight) after which the males quickly die and the now fertilized females attempt to establish new colonies (thus to become egg-laying queens). Colony founding is the most vulnerable phase in an ant colony's life; it often fails due, for example, to predation (Hölldobler and Wilson 1990). Thus, a colony should maximize its reproductive success by producing an optimal number of the reproductive castes. 
Our informants yet point to a decrease in queen brood availability (compared to five and ten years before the time of investigation) and explain it by an increase in number of collectors and a decrease in forest area. An increase in number of collectors likely causes more frequent brood removal from a single colony, which may obstruct the development of queen brood into mature brood (final instar larvae and pupae). However, the effect of queen brood removal on subsequent brood production remains unknown. A decrease in forest area indicates loss of suitable nesting sites and thus a decrease in queen brood availability via a decrease in colony abundance. This, in turn, likely causes more frequent brood removal from a single colony. The collectors nevertheless do not deem a conservation strategy for this resource necessary. A collector said, "the ants always have been and always will be present [as merely relatively few worker ants ('mothers' according to the collectors) are removed during collection]." O. smaragdina then currently does not act as a flagship/umbrella species in indigenous practices and its potential may not be strong in the Vientiane Plain, Lao PDR.

O. smaragdina (semi-)cultivation and agroforestry

The development of O. smaragdina (semi-)cultivation can benefit from an input of indigenous knowledge which is relatively detailed due to the intensive use of O. smaragdina as human food. The collectors' knowledge of O. smaragdina seasonality is consistent with scientific findings in Wongwiggarn and Leksawasdi (1988). Yet, making correct predictions of nest contents remains challenging. The factors inducing the onset and conclusion of O. smaragdina queen brood production need to be discovered and understood. This understanding can in turn form the basis in developing means to predict and manipulate queen brood production of an individual colony. As such, the collectors' belief in the role of water bodies and rain (water promoting larval growth) deserves examination. Further, the collectors' knowledge of O. smaragdina favored host tree species and their nesting preference near open spaces, as confirmed by Hölldobler (1983), can form the basis in developing agroforestry practices of $O$. smaragdina queen brood and tree crops in accordance with local needs.

A number of additional constraints and possibilities to O. smaragdina (semi-)cultivation are identified from the collection practices and the indigenous knowledge embedded therein. First, O. smaragdina is an open access resource. Ownership does not occur and, since not even in home gardens, (semi-) cultivating O. smaragdina would require a conceptual change: from open access natural resource to privately owned (semi-)cultivated product. Second, the aggressiveness of $O$. smaragdina to humans is a possible reason why the potential of $O$. smaragdina in agroforestry is under-researched (Van Mele 2008). Some informants do not wish O. smaragdina to inhabit the trees in their home garden. However, measures to reduce nuisances are applied by collectors, such as the use of starch powder on the collecting pole preventing ants crawling along it and attacking the collector (see also Sribandit et al. 2008; Van Mele et al. 2009). Such measures can be improved as they have been in beekeeping. Third, the land area owned by a family may not be sufficiently large to make O. smaragdina (semi-)cultivation feasible. Agroforestry practices in which O. smaragdina (semi-)cultivation is embedded are economically likely most beneficial. Last, due to the respondents' belief that each major worker ant is an individual able to reproduce and cooperate with any other major worker, an input from western science on ant biology and ecology including queen biology and the concept of individual colonies is required either through formal education systems or training and workshop programs.

\section{Conclusion}

Indigenous knowledge of O. smaragdina in the Vientiane Plain, Lao PDR, is relatively detailed due to its intensive use as human food. Ant brood collection practices seem to assure colony survival as the gravid queen is rarely removed and unknown to most ant brood collectors, and the fraction of workers and worker brood removed does not likely impede the maintenance and ecological role of a colony. Yet, with decreasing forest area the population of O. smaragdina colonies seems in decline. Whether the ant brood collection itself negatively affects subsequent queen brood production and the number of newly founded colonies remains uncertain. The indigenous knowledge and practices provide scope for further developments in O. smaragdina exploitation, notably in the (semi-)cultivation of O. smaragdina incorporated in agroforestry practices whereby the predictability and availability of queen brood is increased.

\section{Acknowledgements}

This study was conducted under an Agreement between the Department of Plant Sciences, Wa- 
geningen University, and the Faculty of Science, National University of Laos. Tree species is identified by Mr. Soulivanh Lanorsavanh and Ms. Khamfa Chanthavongsa, Department of Biology, Faculty of Science, National University of Laos. Mr. Thananh Khotpathoom, Faculty of Forestry, National University of Laos, kindly identified forest ecosystems from photographs. Dr. Decha Wiwatwitaya of the Faculty of Forestry, Kasetsart University, Thailand, is thanked for identifying ant samples. Dr. Rod Eastwood of the Museum of Comparative Zoology, Harvard University, is thanked for identifying butterfly samples.

\section{Declarations}

Permissions: Ministry of Education of the Lao PDR and Faculty of Science at the National University of Laos.

Sources of Funding: None declared.

Conflicts of Interest: None declared.

\section{References Cited}

Ayieko, M. A., G. O. Obonyo, J. A. Odhiambo, P. L. Ogweno, J. Achacha, and J. Anyango. 2011.

Constructing and Using a Light Trap Harvester: Rural Technology for Mass Collection of Agoro Termites (Macrotermes subbylanus). Research Journal of Applied Sciences, Engineering and Technology 3:105-109.

Berkes, F. 2008. Sacred Ecology. Routledge, New York.

Choo, J., E. L. Zent, and B. B. Simpson. 2009. The Importance of Traditional Ecological Knowledge for Palm-Weevil Cultivation in the Venezuelan Amazon. Journal of Ethnobiology 29:113-128.

Crozier, R. H., P. S. Newey, E. A. Schlüns, and S. K. A. Robson. 2009. A Masterpiece of Evolution Oecophylla Weaver Ants (Hymenoptera: Formicidae). Myrmecological News 13:57-71.

Durst, P. B., and K. Shono. 2010. Edible Forest Insects: Exploring New Horizons and Traditional Practices. Paper Presented at the FAO Regional Office for Asia and the Pacific meeting on Forest Insects as Food: Humans Bite Back, a Workshop on AsiaPacific Resources and their Potential for Development. Chiang Mai, Thailand.

Gupta, C. S. 1968. Studies on the Population Structure of the Nests of the Indian Red Ant - Oecophylla smaragdina Fabr. (Formicidae - Hymenoptera). Paper Presented at the Symposium on Recent Advances in Tropical Ecology of the International
Society for Tropical Ecology. Varanasi, India.

Heinze, J. and L. Keller. 2000. Alternative Reproductive Strategies: A Queen Perspective in Ants. Trends in Ecology and Evolution 15:508-512.

Hölldobler, B. 1983. Territorial Behaviour in the Green Tree Ant (Oecophylla smaragdina). Biotropica 15:241-250.

Hölldobler, B. and E. O. Wilson. 1983. Queen Control in Colonies of Weaver Ants (Hymenoptera: Formicidae). Annals of the Entomological Society of America 76:235-238.

Hölldobler, B. and E. O. Wilson. 1990. The Ants. Springer-Verlag, Heidelberg Berlin.

Hölldobler, B. and E. O. Wilson. 2009. The Superorganism: The Beauty, Elegance, and Strangeness of Insect Societies. W.W. Norton, New York.

Lim, G. T. 2007. Enhancing the Weaver Ant, Oecophylla smaragdina (Hymenoptera: Formicidae), for Biological Control of a Shoot Borer, Hypsipyla robusta (Lepidoptera: Pyralidae), in Malaysian Mahogany Plantations. Unpublished Doctoral Dissertation, Department of Entomology, Virginia Polytechnic Institute and State University, Blacksburg, VA.

Meyer-Rochow, V. B., K. Nonaka and S. Boulidam. 2008. More Feared than Revered: Insects and their Impact on Human Societies (with Some Specific Data on the Importance of Entomophagy in a Laotian Setting). Entomologie Heute 20:3-25.

Mingbuapha, K. and B. Poomsan Becker. 2003. LaoEnglish Dictionary. Paiboon Publishing, Bangkok.

Offenberg, J. and D. Wiwatwitaya. 2010. Sustainable Weaver Ant (Oecophylla smaragdina) Farming: Harvest Yields and Effects on Worker Ant Density. Asian Myrmecology 3:55-62.

Ramos-Elorduy, J. 2006. Threatened Edible Insects in Hidalgo, Mexico and Some Measures to Preserve Them. Journal of Ethnobiology and Ethnomedicine 2:51.

Rastogi, N. 2007. Seasonal Pattern in the Territorial Dynamics of the Arboreal Ant Oecopbylla smaragdina (Hymenoptera: Formicidae). Journal of the Bombay Natural History Society 104:Jan-Apr.

Sribandit, W., D. Wiwatwitaya, S. Suksard and J. Offenberg. 2008. The Importance of Weaver Ant (Oecophylla smaragdina Fabricius) Harvest to a Local Community in Northeastern Thailand. Asian 
Myrmecology 2:129-138.

Van Huis, A., J. Van Itterbeeck, K. Klunder, E. Mertens, A. Halloran, G. Muir and P. Vantomme. 2013. Edible Insects: Future Prospects for Food and Feed Security. FAO, Rome.

Van Mele, P. 2008. A Historical Review of Research on the Weaver Ant Oecophylla in Biological Control. Agricultural and Forest Entomology 10:13-22.

Van Mele, P., N.T.T. Cuc, Z. Seguni, K. Camara and J. Offenberg. 2009. Multiple Sources of Local Knowledge: A Global Review of Ways to Reduce Nuisance from the Beneficial Weaver Ant Oecophylla. International Journal of Agricultural Resources, Governance and Ecology 8:484-504.

Wongwiggarn, R. and P. Leksawasdi. 1988. Nest, Population and Development of Weaver Ant
Oecophylla smaragdina F. Paper Presented at the 26th Kasetsart University Conference, Bangkok, Thailand.

\section{Biosketches}

Joost Van Itterbeeck is a PhD student at the Laboratory of Entomology, Wageningen University.

Niane Sivongxay is a lecturer at the Department of Biology, National University of Laos.

Bouthob Praxaysombath is head of the Department of Biology, National University of Laos.

Arnold van Huis is a tropical entomologist at the Laboratory of Entomology, Wageningen University. 